\title{
A ÍNDIA COMO TERCEIRO INTERESSADO NA DISPUTA DE PODER SINO-ESTADUNIDENSE ${ }^{1}$
}

\author{
INDIA AS AN INTERESTED THIRD PLAYER IN THE SINO-US POWER \\ DISPUTE
}

DOI: http://dx.doi.org/10.5380/cg.v9i1.70693

\author{
João Miguel Villas-Bôas Barcellos²
}

\begin{abstract}
Resumo
Em 2007 Índia e Estados Unidos assinaram um importante documento de cooperação nuclear, o que significou o reconhecimento da condição de país com status nuclear pela maior potência mundial. A Índia se tornou uma potência regional com ambições globais de fundamental importância para o equilíbrio de poder na região que, após o avanço do poder do "Império do Meio", ficou afetado e pende pare este. Em que medida ela - a Índia - está disposta a cooperar com os Estados Unidos pela contenção da expansão do poder e influência chinesa no continente asiático? Outra indagação de fundo é: os Estados Unidos estão dispostos a fortalecer e apoiar a Índia até as últimas consequências, nessa política de contenção chinesa? Índia e China podem cooperar e alterar substancialmente a ordem de poder asiática? Nosso trabalho tem como objetivo analisar estas questões de fundo complexas e ainda pouco claras, uma vez que seus desdobramentos estão em pleno vigor. Para tal, ele será dividido em três partes, mais uma introdução e conclusão. Na primeira, apresentaremos o quadro geopolítico das regiões em que se inserem Índia e China - Sul e Leste asiático -; na segunda, analisaremos as relações entre os Estados Unidos e a Índia focando na parceria nuclear e na cooperação pela contenção chinesa; na terceira parte, examinaremos os desafios e possíveis cenários da questão; por fim, teremos uma quarte parte, na qual analisaremos a possibilidade de uma cooperação entre India e China por meio da Belt and Road Initiative.
\end{abstract}

Palavras-Chave: Índia; Estados Unidos; China; Contenção; Cooperação nuclear.

\begin{abstract}
In 2007, India and the United States signed an important document of nuclear cooperation, which meant the recognition of the Indian nuclear status by the world's largest power. India has become a regional power with global ambitions and has fundamental importance for the balance of power in the region which, after the advancement of the power of the "Middle Empire", has been affected and tilts towards this. To what extent is India willing to cooperate with the United States to curb the expansion of Chinese power and influence on the Asian continent? Another substantive question is: is the United States willing to strengthen and support India to its ultimate consequences in this policy of Chinese containment? Can India and China cooperate and substantially alter the Asian power order? Our work aims to analyze these complex and still unclear issues, as their developments are in full force. To this end, it will be divided into four parts plus an introduction and conclusion. In the first, we will present the geopolitical picture of the regions in which India and China South and East Asia - are inserted; In the second, we will analyze US-India relations focusing on nuclear partnership and cooperation for Chinese containment; In the third part, we will examine the challenges and possible scenarios of the issue. Finally, we will have a fourth part in which we will consider the possibility of cooperation between India and China through the Belt and Road Initiative.
\end{abstract}

Keywords: India; United States of America; Containment; Nuclear Cooperation.

${ }^{1} \mathrm{O}$ presente artigo foi financiado com recursos da Coordenação de Aperfeiçoamento de Pessoal de Nível Superior (CAPES).

${ }^{2}$ Doutorando do Programa de Pós-Graduação em Economia Política Internacional (PEPI) - Instituto de Economia - UFRJ e pesquisador do núcleo de Análise da Conjuntura da Escola de Guerra Naval. E-mail: joao.barcellos@pepi.ie.ufrj.br. ORCID: https://orcid.org/oooo-0001-5457-450X. 


\section{INTRODUÇÃO}

A Índia é uma potência regional com claras aspirações a tornar-se uma grande potência (NOLTE, 2011). Desde sua independência, em 1947, o país busca atuar no Sistema Internacional (SI), de maneira autônoma e não alinhada. Desse modo, transformou-se em um dos líderes do Terceiro Mundo e do G-77 durante o período da Guerra Fria (1947-1991). Apesar de alterar parcialmente sua inserção internacional nos anos 1990, com a política do Look East, a Índia não abandonou por completo a estratégia de não alinhamento. A partir dos anos 2000, porém, o país procurou agir com mais responsabilidade em temas relevantes de sua política externa, como não proliferação e comércio internacional (NARLIKAR, 2009).

Um dos elementos da política externa indiana que passaram por revisão foi a relação bilateral com os Estados Unidos. Historicamente, ou até o início dos anos 2000, os governos do país sul-asiático viam Washington com desconfiança, haja vista a parceria com o Paquistão e as críticas ao programa nuclear indiano. Todavia, as negociações para o acordo nuclear de 2007 com os Estados Unidos e a ascensão chinesa alteraram a abordagem mais crítica à superpotência mundial, o que possibilitou uma mudança de rumos na política bilateral e uma janela de oportunidade para cooperação e parcerias variadas.

Tal mudança passa pelos governos dos primeiros ministros Manmohan Singh (2004-2014, Partido do Congresso) e Narendra Modi (Partido do Povo, ou Bharatiya Janata, 2014-2018) e ilustra um elemento de pragmatismo na política externa indiana que deve ser melhor entendido. Diferentemente do que se acredita, em matéria de inserção internacional, os partidos não se diferenciam muito. As retóricas são diferentes, em alguns temas, porém, as prioridades convergem, como ficou claro no acordo nuclear com os Estados Unidos, na defesa dos interesses estratégicos no campo nuclear, na reforma das instituições internacionais de Bretton Woods, nas relações com suas principais ameaças geopolíticas (China e Paquistão) e na busca por uma vaga de membro permanente no Conselho de Segurança das Nações Unidas. Com efeito, não obstante as semelhanças, é importante ressaltar que Narendra Modi foi eleito em 2014 com uma retórica de política externa pragmática, sem os apelos morais tradicionalmente advogados pelo Partido do Congresso. Houve inclusive uma associação entre sua plataforma de inserção internacional com o clássico Arthashastra, de Kautilya (MISRA, 2016).

Nosso objetivo neste trabalho é analisar, especificamente, a maneira pela qual a Índia se coloca como terceiro interessado diante da disputa entre China e Estados Unidos e em que medida a cooperação indo-estadunidense para a contenção chinesa pode prosperar, uma vez que há claros indícios de atritos. Buscamos ainda investigar em que medida a Índia constrói sua política externa autônoma, tendo em vista os resultados pouco expressivos da relação de cooperação com os Estados Unidos para o contraponto às ameaças chinesas. Nesse sentido, é importante ressaltar que 
a China, apesar da histórica rivalidade e das inseguranças causadas à Índia pela sua inserção internacional, oferece um interessante cenário de ganhos econômicos a partir da Belt and Road Initiative $^{3}$. No fundo, o que se analisa e tentar-se-á responder é se a Índia conseguirá: a) tirar proveito da rivalidade sino-estadunidense inserindo-se com maior desenvoltura e autonomia no Sistema Internacional; b) aproveitar os dois tabuleiros estratégicos de cooperação pragmática, com os Estados Unidos e com a China. Como veremos ao longo do artigo, ambos os cenários apresentam ganhos potenciais aos interesses nacionais indianos, o que torna a política externa do país da Ásia meridional mais desafiador.

Para a análise dos objetivos propostos, lançaremos mão de uma metodologia analíticodescritiva baseada em fontes primárias e secundárias. Ademais, utilizaremos conceitos e abordagens das Relações Internacionais, tais como o Realismo e a Interdependência Complexa. Acreditamos que estas abordagens, a despeito de uma confrontação teórica, podem ser utilizadas em contextos e tabuleiros geopolíticos específicos, como será mostrado no trabalho. Assim, se por um lado, a Índia opera de forma realista ao buscar garantir alcançar seus interesses nacionais autonomamente, de modo a construir capacidades de defesa militar em um Sistema Internacional anárquico, por outro, o país visa, simultaneamente, na medida em que o tabuleiro de interesses se altera, à cooperação interestatal (com os Estados Unidos) para defender-se de ameaças chinesas. Nesse sentido, considerando como objetivo primário seus interesses nacionais, a Índia pode ainda, conforme o cálculo estratégico, lançar mão de uma cooperação aparentemente inusitada com seu principal rival (a China), ao rever os ganhos de uma participação no projeto geoeconômico chinês Belt and Road Initiative. Essa complexa trama de interesses ilustra, na mesma medida, quão complexo é o jogo de poder nas relações internacionais, fazendo com que os Estados não se fiem em teorias ou estratégias únicas, haja vista os ganhos potências variados a alcançar-se.

Isso posto, o artigo será dividido em três partes, mais uma introdução e conclusão. Na primeira, apresentaremos o quadro geopolítico das regiões em que se inserem Índia e China - Sul e Leste asiático -, bem como uma breve análise das relações bilaterais; na segunda, investigaremos as relações entre os Estados Unidos e a Índia focando na parceria nuclear e na cooperação pela contenção chinesa; por fim, na terceira parte examinaremos os desafios e possíveis cenários da questão.

\footnotetext{
3 A Nova Rota da Seda ou One Road One Belt (OROB), ou ainda Belt and Road Initiative é um megaprojeto geoeconômico lançado em 2013 pelo presidente chinês Xi Jinping, que pretende construir uma ampla rede de investimentos em infraestrutura em países que estejam dispostos a cooperar com a China. A iniciativa tem como objetivo concluir até 2049 a integração de plataformas de comércio e investimentos na Ásia, África e demais países dispostos a firmar acordos com a China.
} 


\section{O TABULEIRO GEOPOLÍTICO REGIONAL E A MOBILIZAÇÃO DE ÍNDIA E CHINA EM BUSCA DE PROTAGONISMO}

Índia e China são potências de peso e poder diferentes. Historicamente, foram grandes potências econômicas asiáticas, chegando a partilhar metade do PIB industrial global durante séculos, especificamente, até a ascensão do capitalismo europeu do século XVIII (NAYYAR, 2014). Após sofrerem com o domínio imperial inglês - e de outras potências europeias - e perderem a pujança e o protagonismo econômico e geopolítico histórico ao longo do século XIX e primeira metade do século XX, buscaram recuperar o prestígio e o projeto de poder nacional no contexto da ordem internacional de Bretton Woods.

A Índia vem, desde então, construindo sua afirmação como força regional, com claras ambições globais, mas ainda sem a devida condição material - militar e econômica - para ser reconhecida ou respeitada como grande potência. Desde Jawarhalal Nehru (1947-1964), a inserção internacional do país busca a necessária autonomia estratégica, de modo a melhor alcançar os interesses nacionais indianos. A política externa indiana, a despeito de ter desenvolvido uma estratégia de não alinhamento ao longo de décadas, defendeu, igualmente, uma postura universalista ao encontro de temas da agenda do pós-Segunda Guerra. Mohan defende que Nehru buscou dar sentido ao universalismo acima dos elementos que ficaram marcados como tradicionais na política externa indiana, a exemplo do não alinhamento ou da retórica terceiro-mundista do G77. O autor advoga que tais elementos tomaram corpo após sua morte, em 1964 (MOHAN, 2010a). Nesse sentido, as guerras com a China (1962) e com o Paquistão (1965, 1971) tiveram papel relevante na defesa mais enfática da soberania e na construção de meios dissuasórios militares. Além disso, o teste nuclear chinês em 1964 e o Tratado de Não Proliferação Nuclear (TNP), em 1968, colaboraram para isso. Para a Índia, o TNP era discriminatório e não se propunha a combater o privilégio do poder nuclear das grandes potências.

Com os anos 1990 e a abertura econômica parcial (CRUZ, 2007), a política externa indiana buscou aproveitar melhor as relações com os países do leste asiático, por meio da Look East policy implementada pelo governo de Narasimha Rao (MUNI, 2013). A partir de um robusto crescimento econômico, que permanece alto e a afirmação nuclear - com os testes POKHRAN II, em 1998 - a Índia procurou afirmar-se como uma força mundial. A despeito da inserção regional e internacional de caráter mais autonomista, em que o país procura exercer uma liderança no Sul da Ásia por meio da South Asian Association for Regional Cooperation (SAARC) e de grupos de geometria variável, como IBAS, BRICS4 e G20, há especialistas que advogam a tese de que o país buscou afastar-se da estratégia do não alinhamento e executar uma política externa mais

\footnotetext{
4 Exemplo relevante de atuação do BRICS é a criação do Novo Banco de Desenvolvimento e a instituição do Arranjo Contingente de Reservas, que visam a aumentar o papel dos países emergentes, sobretudo dos cinco membros, na ordem econômica e financeira mundial.
} 
"responsável" (NARLIKAR, 2009); isto é, mais de acordo com os elementos da ordem internacional liberal e menos voltada aos princípios norteadores do não alinhamento típico da Guerra Fria. Com a ascensão de Narendra Modi (BJP) ao cargo de primeiro ministro em 2014, a região do leste asiático voltou a ter espaço privilegiado na agenda indiana com a política do Act East - iniciativa lançada durante o $12^{\circ}$. encontro do grupo ASEAN (SINGH, 2018).

Por outro lado, a China, após três décadas de Revolução Cultural, implementada por Mao Tsé-Tung (1949-1976), logrou maior êxito em sua afirmação como potência a partir das reformas de 1978, implementadas por Deng Xiaoping (1978-1992), e se tornou um formidável poder econômico e mesmo militar a ponto de, hodiernamente, disputar espaços estratégicos com a superpotência estadunidense. Nesse sentido, o desenvolvimento de um complexo industrial-militar transformou a China na terceira força militar e no segundo maior orçamento mundial. O arsenal estratégico do país abarca desde a capacidade de fabricar e lançar mísseis balísticos intercontinentais, passando por sofisticado sistema de defesa antiaérea (HQ-16), dispositivos de guerra cibernética até caças de ataque de quinta geração (J-20). O progresso naval é igualmente extraordinário: o país é capaz de projetar e construir uma série de navios de guerra, como fragatas, contratorpedeiros, submarinos (com propulsão nuclear) e porta-aviões, como o "Type oo1A" (o projeto é contar com seis porta-aviões nucleares até 2035). Hoje a China tem uma capacidade de desenvolver, produzir e exportar armamentos de ponta (como o míssil hipersônico Xingkong-2), consolidando sua posição na hierarquia de poder militar global.

Nosso objetivo aqui não é analisar a política externa chinesa em detalhes, pois não é o foco do trabalho, por isso, apresentaremos - como fizemos acima no caso indiano - as linhas gerais da inserção internacional do país. A China se transformou em uma grande potência (GOLDSTEIN, 2005) e vem buscando seu lugar de protagonismo na ordem internacional. O país hoje ostenta a maior economia e a maior participação no comércio mundial (OMC, 2018). A China se transformou no maior exportador e importador mundial e vem buscando construir uma sofisticada rede de influência em todos os quadrantes do globo. O país integra fóruns de grande relevância estratégica, como a Organização para a Cooperação de Shangai, o BRICS, o G20, além de liderar a nova arquitetura financeira mundial, com o Asian Infraestructure Investment Bank (AIIB) e a Belt and Road Initiative (BRI).

É importante ainda, ressaltar que a ascensão de Donald Trump como presidente dos Estados Unidos e sua política externa antiliberal, crítica da ordem internacional vigente, encurtaram o caminho para uma maior liderança mundial chinesa. Atualmente, a China busca uma inserção internacional mais responsável e se coloca como referência para a estabilidade dos principais pilares da ordem política e econômica globais.

Todavia, apesar de colocar-se como "potência responsável”, a China é vista com apreensão e desconfiança por muitos países, especialmente pela Índia, que percebe sua expansão de poder como agressiva (RAJAGOPALAN, 2017). Desse modo, as relações sino-indianas se mantêm dentro 
de uma realidade competitiva e delicada. Mohan estabelece cinco pontos relevantes na trajetória das duas potências em franca ascensão: 1) são economias ligadas à globalização e integração regional, além de serem, hodiernamente, motivadoras da ordem internacional, diferentemente das críticas do passado; 2) devido ao crescimento econômico robusto, ambas devem tornar-se polos gravitacionais e alterar a geopolítica da região; 3) Índia e China estão cada vez mais dependentes do comércio marítimo, o que faz que elas invistam pesadamente em infraestrutura e poder naval; 4) construção de marinhas de guerra compatíveis com as ambições e o crescimento, ou seja, desenvolver uma "Marinha de águas azuis" capaz de acompanhar os interesses econômicos no globo; 5) o resgate da tradição naval outrora importante (MOHAN, 2010a).

Estes cinco pontos levantados por Haja Mohan são fundamentais para entendermos em que medida Índia e China disputam espaços de poder - de forma assimétrica, é verdade. Os pontos 3 e 4 são particularmente importantes e têm sido objeto de grande esforço e investimento dos dois países, que possuem cada vez mais poder militar e são consideradas terceira (China) e quarta (Índia) forças militares mundiais (GLOBALFIREPOWER, 2019).

Outra sensível questão para a Índia é tentar conter o "bloqueio" geoeconômico chinês do "colar de pérolas" (string of pearls) 5 que vem sendo fortalecido com o projeto Belt and Road Initiative, (BRI) (ASHRAF, 2017). Nesse sentido, a contenção indiana seria o “Grande Jogo" chinês (NALAPAT, 2006). A parceria sino-paquistanesa é também motivo de preocupação indiana, principalmente, em função do Corredor Econômico China-Paquistão (China-Pakistan Economic Corridor, CPEC), além da cooperação no âmbito militar.

Considerando que o continente asiático se tornou o epicentro da economia global, e que Índia e China são dois dos mais importantes atores do tabuleiro geopolítico e econômico da região, é relevante analisarmos na próxima seção como o país indiano pode agir para conter seu principal rival - ao menos tentar atenuar os efeitos hegemônicos regionais - e afirmar-se como potência regional com aspirações globais.

\section{A RELAÇÃO COM OS ESTAdOS UNIDOS: PARCERIA ESTRATÉGICA OU PRAGMÁTICA?}

A relação entre Índia e Estados Unidos deve ser analisada sob o prisma do contexto da Guerra Fria (1947-1991), particularmente, pela influência soviética no planejamento econômico indiano e nas críticas estadunidenses à estratégia do não alinhamento. Este, que era visto por Washington como uma concepção obsoleta e "neutralista", porém, como a Índia permaneceu na Commonwealth britânica e preservou uma série de valores seculares e democráticos em sua

\footnotetext{
5 Este conceito remete à ideia de que a Índia está cercada por uma rede de bases militares, portos e constrangimentos econômicos chineses. Para mais informações, ver: KHURANA (2008).
} 
constituição, os Estados Unidos mantiveram uma postura menos rígida, o que permitiu que o país fosse o principal doador de recursos ao país asiático nos anos 1950 (PANT, 2015).

Todavia, a partir do momento em que os Estados Unidos passaram a fornecer ajuda militar ao Paquistão - após este aderir ao Central Treaty Organization (CENTO, também conhecido como "Pacto de Bagdá”) em 1955 - as relações com a Índia sofreram sérias consequências. Em 1971 a situação bilateral piora, em função da assinatura do Tratado de Cooperação e Amizade Indosoviético. Em 1974 a Índia faz seu primeiro teste nuclear (POKHRAM I), e em 1978 os EUA cortaram qualquer tipo de assistência e cooperação na área nuclear com a o país (WEISS, 2007).

Apesar de as relações terem melhorado nos anos 1990, após a realização dos novos testes nucleares, em 1998 (POKHRAM II) ${ }^{6}$, os Estados Unidos voltam a criticar o programa nuclear indiano e aplicam sanções econômicas. Estas duram até setembro de 2001, quando o presidente estadunidense George W. Bush retira as sanções (WAGNER, 2001). No ano anterior, em 2000, Condoleezza Rice escreve um artigo para a campanha eleitoral em que afirma que os Estados Unidos deveriam prestar mais atenção no papel da Índia no equilíbrio regional de poder considerando que “(...) a Índia é um elemento do cálculo chinês e ela deveria ser dos Estados Unidos também. Ela ainda não é uma grande potência, mas tem o potencial de emergir como uma” (RICE, 2000, p. 56, tradução nossa)7. A opinião de Rice sobre o papel indiano na região e a possível parceria com os Estados Unidos para a manutenção do equilíbrio de poder asiático é reforçada oito anos adiante em novo artigo na Foreign Affairs, em que a então Secretária de Estado atesta que as relações bilaterais nunca foram tão amplas e boas (RICE, 2008).

Após a suspensão das sanções, em 2005, Índia e EUA iniciaram as tratativas para o Acordo Nuclear que entrará em vigor em outubro de 2008. Desse modo, em 2010, Hilary Clinton declarou que a Índia era um parceiro indispensável e, como consequência, os países organizaram o primeiro Diálogo Estratégico, que doravante será reproduzido anualmente. É importante ressaltar que, ainda em 2010, o presidente Barack Obama declarou apoio ao pleito indiano para um assento permanente no CSNU.

A política externa do presidente Obama para a Ásia reafirma o papel fundamental indiano da reconfiguração de poder no continente. Assim, a Índia se torna peça fundamental na contenção da crescente influência chinesa no continente (BURGESS, 2015). Exemplo do êxito da parceria se dá em 2016, ano em que os EUA reconhecem a Índia como major defence partner (um parceiro estratégico em defesa) e em 2018, quando Trump e Modi assinaram o Communications

\footnotetext{
${ }^{6}$ Sobre os testes de 1998, é interessante vermos a justificativa geopolítica dada pelo Primeiro Ministro Vajpayee ao presidente Clinton no mesmo ano: havia uma necessidade de realizar-se os testes devido ao fato de a China ser "um estado nuclear aberto em nossas fronteiras, um estado que cometeu agressão armada contra a Índia em 1962" e "persiste uma atmosfera de desconfiança”(VAJPAYEE, apud SCOTT, 2008, p. 04, tradução nossa).

7 No original: "India is an element in Chinas calculation, and it should be in America's, too. India is not a great power yet, but it has the potential to emerge as one".
} 
Compatibility and Security Agreement (COMCASA), acordo na área de defesa que permite à Índia utilizar equipamentos de comunicação sensíveis dos EUA (PANDA, 2018).

Vale mencionar que a Índia aumentou em 557\% a importação de armamento estadunidense entre 2013 e 2017, chegando à cifra de US\$ 18 bilhões (SIPRI, 2018). Ainda em 2017, a Índia encomendou 700 mil fuzis de assalto. Além dos fuzis, a Marinha indiana comprou em 2009 oito aviões de patrulha marítima P-8 Poseidon (Boeing) e, em 2019, mais dez (GADY, 2019). Por fim, o presidente Donald Trump aprovou a venda de 13 canhões navais MK-45 por pouco mais de US\$ 1 bilhão, em novembro de 2019 (SINDWANI, 2019).

Contudo, apesar dos avanços no campo da defesa e segurança, ao observarmos a relação bilateral indo-estadunidense, hodiernamente, há elementos de atrito relevantes. Nesse sentido, o governo de Donald Trump pressiona a Índia a não fechar a compra do poderoso sistema de defesa russo S-400 Triumf, além da retirada do país do status de parceiro comercial preferencial no sistema geral de preferências da OMC. Outro ponto que incomodou bastante os indianos foi a aplicação de sanções às nações comercialmente parceiras do Irã. A Índia era um dos maiores importadores de petróleo do país persa. Possíveis sanções devido ao Countering America's Adversaries Through Sanctions Act (CAATSA) estão sendo avaliadas em função da aquisição do equipamento de defesa russo citado acima. Resta saber se o governo de Trump vai impor sanções ao parceiro estratégico, haja vista a afirmação do Ministro das Relações Exteriores indiano, Jaishankar, de que o país não abrirá mão da compra junto aos russos (KAURA, 2019).

As relações comerciais bilaterais vêm aumentando desde 2008, assim como os investimentos externos diretos (IED). Em 2018, a Índia foi o $12^{\circ}$. maior destino das exportações estadunidenses e o $10^{\circ}$. parceiro comercial dos Estados Unidos, ao passo que, no mesmo ano, o país americano foi o segundo principal destino das exportações indianas e, em 2019, o principal parceiro comercial, ultrapassando a China (THE ECONOMIC TIMES, 2020) Ainda em 2018, o estoque de IED estadunidense na Índia foi de US\$46 bilhões, e o indiano nos EUA de US\$9,6 bilhões (AKTHAR; KRONSTADT, 2020).

Por fim, cabe ressaltar a história relação de "fuga de cérebros" da Índia para os Estados Unidos, que ajuda a formar um amplo quadro de capital humano especializado em inovação tecnológica e engenharia no país. Contudo, essa tendência pode ser revista, haja vista o quadro de retorno de milhares de cientistas indianos devido às políticas de imigração de Donald Trump e ao constante crescimento econômico indiano ao longo dos últimos anos (SATALINE, 2017).

Na próxima seção, analisaremos os limites e desafios à Índia no complexo jogo de forças que se desdobram a partir da disputa sino-estadunidense (USA, 2019). 


\section{DESAFIOS E LIMITES À INSERÇÃO INTERNACIONAL INDIANA: HÁ ESPAÇO PARA AUTONOMIA DIANTE DA DISPUTA HEGEMÔNICA SINO-ESTADUNIDENSE?}

Mohan sintetiza bem a relação triangular - Índia-China-Estados Unidos - e suas possibilidades, expectativas e limites:

Há muitas maneiras pelas quais o relacionamento triangular pode se desdobrar. Alguns americanos veem a importância de acomodar a ascensão da China através da construção de um condomínio; alguns outros veem a Índia como um balanceador natural contra a ascensão da China. Ainda outros americanos argumentam que Washington deve equilibrar-se contra Pequim e Delhi. Alguns em Pequim temem que o poder naval da Índia, atuando em colaboração com os Estados Unidos e o Japão, possa atingir os interesses marítimos vitais da China. Há outros em Pequim que especulam que a ascensão do poder naval indiano é uma ameaça aos Estados Unidos e não à China. Delhi é bastante reservada para identificar a hierarquia de suas ameaças. Em consonância com os líderes chineses, falamos sobre a promoção de um mundo multipolar; apertando as mãos dos americanos proclamamos uma aliança natural com os Estados Unidos (MOHAN, 2010c, online, tradução nossa) ${ }^{8}$.

Podemos depreender da citação acima que a relação triangular - ou bilateral indoestadunidense para conter a China - é complexa e muito pouco dedutível. Por tratar-se de países com capacidades assimétricas e objetivos geopolíticos diferentes, quais sejam, manter (EUA) ou aumentar (China e Índia, em graus distintos) poder, as análises tendem a ser, igualmente, complexas e mesmo imprecisas. Destarte, nosso objetivo neste tópico será o de tentar investigar como a Índia aproveita os espaços e se relaciona com as duas outras potências do triângulo.

As relações indo-chinesas foram e ainda são marcadas por tensões, conflitos e disputas. A despeito de haver contínuo esforço político-diplomático de ambas as partes, o nível de instabilidade e incompreensões tem sido a regra. Os problemas de fronteira ilustram bem esta questão, e o efeito psicológico impregnado nas sociedades cumpre, igualmente, o papel de manter a percepção do outro como inimigo ou rival. De todo modo, a despeito de iniciativas dos dois governos, as tensões são inevitáveis, uma vez que um dos principais espaços geopolíticos de expansão do poder chinês é o Oceano Índico - declaradamente o principal espaço estratégico indiano - e a influência sobre países vizinhos da nação hindu. Como bem salienta Scott:

Como o Ministro das Relações Exteriores da Índia, Yashwant Sinha, admitiu, China e Índia precisam "tentar assegurar que cada um tenha espaço estratégico

\footnotetext{
${ }^{8}$ No original: "There are many ways in which the triangular relationship could unfold. Some Americans see the importance of accommodating the rise of China through the construction of a condominium; some others see India as a natural balancer against China's rise. Yet other Americans argue that Washington must balance against both Beijing and Delhi. Some in Beijing worry that India's naval power, acting in collaboration with the United States and Japan, could hit at the vital maritime interests of China. There are others in Beijing who speculate that the rise of Indian naval power is a threat to the United States rather than to China. Delhi is itself quite coy about identifying the hierarchy of its threats. Standing with Chinese leaders, we talk about the promotion of a multi-polar world; shaking hands with the Americans, we proclaim a natural alliance with the United States".
} 
suficiente”. Entretanto, seus “espaços estratégicos” estão, de várias maneiras, na mesma arena espacial, isto é, Pacífico Asiático, Sul da Ásia, Oceano Índico e Ásia Central. Ambos os Estados estão engajados em "controlar os espaços" diretamente e indiretamente e, às vezes, competindo um com o outro (SCOTT, 2008, p. 02, tradução nossa) ${ }^{9}$.

É o que o autor chama de “'o grande jogo das grandes potências' entre Índia e China e 'a lógica da geografia" (SCOTT, 2008) ${ }^{10}$. Por isso, a reação indiana é militarmente contundente: o país vem ampliando seus dispositivos de defesa, sobretudo navais, para tentar instrumentalizar uma política de negação do mar à China. Além de fragatas e contratorpedeiros, o país vem expandindo sua autonomia tecnológica no setor e conseguiu um feito digno de nota: fabricar um navio aeródromo nacionalmente (além de estar fabricando o segundo). O objetivo precípuo do país é ter uma "Marinha de águas azuis", com duzentos navios de guerra até 2027, capaz de atuar em todos os oceanos (Vice-Almirante Muruguesan apud The Economic Times). Nesse sentido,

As frases de "Aden a Malaca" ou "de Suez ao Mar do Sul da China" foram reinjetadas no discurso de segurança nacional. Para mostrar como isso não é conversa vazia, uma série de operações da Marinha indiana, que tem mostrado a bandeira tricolor em águas tão longínquas quanto o Atlântico Norte e o Pacífico Sul e do Mediterrâneo ao Mar do Japão. Mais importante ainda em atividades antipirataria no Golfo de Aden (desde 2008) e as operações de socorro no Mediterrâneo (2006) e no Índico (2004-2005) tem demonstrado a capacidade crescente da Marinha indiana e da política de Nova Délhi de atuar distante da sua costa (MOHAN, 2010c, online, tradução nossa) ${ }^{11}$.

É importante salientar que a Índia vem desenvolvendo, há décadas, um complexo industrial-militar capaz de planejar, desenvolver e fabricar carros de combate (Arjun), mísseis de curto, médio e longo alcance (Prithvi, Brahmos e Agni, respectivamente), submarinos nucleares (Scorpènne, em parceria com a França), aviões de combate leve (Tejas), além da reconhecida competência no campo de satélites, especialmente, pelo míssil antissatélite recentemente testado.

No que concerne às relações indo-estadunidenses, os problemas são consideravelmente menores, porém não deixam de apresentar elementos suficientes de inseguranças. Desse modo, alguns questionamentos parecem-nos relevantes: i) até que ponto os Estados Unidos enxergam a Índia como parceira? Apenas na contenção chinesa? ii) À medida que a Índia se empodera, econômica e militarmente, ela tende a buscar inserir-se no Sistema Internacional com mais

\footnotetext{
9 No original: "As India's Foreign Minister Yashwant Sinha admitted, China and India needed to "try to ensure that each has sufficient strategic space".6 However their 'strategic space' is in various ways the same spatial arena, i.e., Pacific Asia, South Asia, the Indian Ocean and Central Asia. Both states are engaged in "mastering space", directly and indirectly, and at times in competition with each other".

${ }^{10}$ No original: "The Great Power 'Great Game' between India and China: 'The Logic of Geography”.

${ }^{11}$ No original: "The phrases from 'Aden to Malacca' or 'the Suez to the South China Sea' were re-injected into the national security discourse. That this is not an empty talk is reflected in the operations of the Indian Navy that has frequently shown the Tricolour in waters as far apart as the North Atlantic and the South Pacific and from the Mediterranean to the Sea of Japan. More importantly, anti-piracy activity in the Gulf of Aden (since 2008) and relief operations in the Mediterranean (2006) and the Indian Ocean (2004-05) have underlined the growing capacity of the Indian Navy and the new political will in Delhi to act far from its shores".
} 
autonomia e altivez. Em que medida os Estados Unidos estão preparados para conviver com mais uma grande potência? iii) No caso indiano, naturalmente há uma diferença político-institucional para com a China, porém, são a democracia e alguns valores seculares elementos suficientes para atestar o status de parceiro estável? Estes questionamentos aparecem como pontos fundamentais para a compreensão do espaço de manobra que a Índia pode ocupar de fato no delicado tabuleiro geopolítico regional e mesmo global.

Mohan chama atenção para algumas questões acerca da ascensão indiana e a maneira como os Estados Unidos tendem a lidar com este fato. Se por um lado a contenção chinesa é importante e a Índia é aliada fundamental - e é também, o “pesadelo chinês” (KNODELL, 2016) -, por outro, há aspectos que dizem respeito à agenda global e sua administração que a Índia deveria preparar-se para coadministrar, como espaços marítimos, aéreos e o ciberespaço (MOHAN, 2010b).

Apesar de existirem elementos importantes de cooperação e parceria entre Índia Estados Unidos, como valores democráticos ${ }^{12}$ e percepção semelhante sobre a ameaça chinesa, há quem entenda que o comportamento estadunidense seja ambivalente. Não há ênfase a respeito do verdadeiro potencial de parceria com Nova Délhi na gestão dos assuntos da agenda global (MOHAN, 2010b).

Outra preocupação indiana é o igualmente dúbio comportamento dos Estados Unidos com relação à China. A citação em seguida ilustra isso:

Os tomadores de decisão indianos se preocupam tanto acerca de um condomínio China-EUA (ou G2) quanto sobre uma crise ou conflito sino-estadunidense. Há preocupação a respeito da confiabilidade dos EUA, no sentido de que os EUA acabarão escolhendo a China em função da maior relação de interdependência econômica sino-estadunidense e/ou deixar a Índia abandonada (MADAN, 2014, online, tradução nossa) ${ }^{13}$.

Apesar de as relações sino-estadunidenses não serem estáveis e o país comunista ser tratado por Washington como uma ameaça, há uma percepção importante para alguns analistas de que o futuro da ordem global passa pela estabilidade das relações entre ambas na manutenção e geração de bens públicos internacionais (NYE, 2018). Desse modo, cabe a pergunta: há espaço para a Índia nesse potencial condomínio bipolar?

A história da luta contínua por poder e riqueza entre as unidades políticas nos ensina que quem não sobe, cai (ELIAS, 1993). Ou seja, para que a Índia se insira no SI com mais autonomia e espaço de manobra, ela terá de agir estrategicamente como terceiro interessado na relação sino-

\footnotetext{
12 Este ponto é ressaltado por vários analistas, porém, desde a ascensão de Narendra Modi, em 2014, o nacionalismo hindu (movimento hindutva) vem crescendo fortemente e ameaçando a ordem secular constitucional formal.

13 No original: "Indian policymakers worry both about a China-U.S. condominium (or G-2) and a ChinaU.S. crisis or conflict. There is concern about the reliability of the U.S., with the sense that the U.S. will end up choosing China because of the more interdependent Sino-American economic relationship and/or leave India in the lurch".
} 
estadunidense, da mesma forma que a China fez a partir dos anos 1970 diante da disputa entre EUA e URSS.

A Índia vem construindo, paulatinamente, capacidades cada vez mais autônomas no campo econômico, militar e tecnológico, que permitem ao país uma inserção internacional mais assertiva e livre de constrangimentos. Por isso, a aliança com os Estados Unidos é relevante por um lado, pois fortalece o elemento que mais lhe faz falta na relação com a China, qual seja, poder militar; porém, por outro lado, o país não tem garantias de uma relação que lhe permita independência de manobra, como ficou demonstrado no caso das sanções do passado e das possíveis de agora. Nesse sentido, a Índia busca ampliar seu quadro de parcerias estratégicas, como Rússia e Japão, de modo a não ficar refém do arbítrio ou volatilidades dos Estados Unidos.

\section{BELT AND ROAD INITIATIVE: UMA OPORTUNIDADE PARA A ÍNDIA?}

De acordo com Joshi, há quatro "Cs" que moldam as relações entre China e Índia: conflict, competition, cooperation e containment (conflito, competição, cooperação e contenção) (JOSHI, 2018). Tendo em vista esta perspectiva, pode-se inferir que o conflito e a competição têm um potencial ambivalente, isto é, podem tanto levar as duas nações asiáticas à guerra - o que seria catastrófico - quanto estimular um passo mais ousado na direção da cooperação. Nesse sentido, acreditamos que a BRI abre uma possibilidade para a Índia participar de uma nova arquitetura da ordem econômica internacional. Muitos países já assinaram memorandos de entendimento para entrarem no megaprojeto econômico-comercial chinês (incluindo países europeus, africanos, latino-americanos e asiáticos). O que impede que a Índia adira? Questões de ordem geopolítica ou econômicas?

Do ponto de vista das relações econômico-comerciais, o déficit comercial indiano é um dos principais problemas. Há um grande superávit chinês no fluxo bilateral de aproximadamente 95 bilhões de dólares. (GE, 2019). No entanto, um desequilíbrio persiste no comércio China-Índia. A Índia está buscando maior acesso ao mercado chinês de produtos agrícolas e também quer fortalecer as trocas entre as pessoas com a China, exportando serviços de software, setor em que a Índia tem vantagem. As diferenças nas estruturas comerciais também preocupam a Índia, que exporta produtos de baixo custo e valor adicionado, como minério de ferro e produtos agrícolas, enquanto as exportações chinesas são bens de maior valor adicionado, como high-tech.

A participação indiana em arranjos institucionais, como BRICS, Asian Investiment and Infrastructure Bank (AIIB) ou Organização para a Cooperação de Xhangai (OCX) não alterou a desconfiança com que o país enxerga a BRI. Esta percepção decorre, sobretudo, em função das pressões geopolíticas no Índico e da íntima cooperação sino-paquistanesa via CPEC (SACHDEVA, 2018). O CPEC é considerado um problema também, porque, além de revelar-se uma ameaça 
geoeconômica, é um projeto que se utiliza de região reivindicada pela Índia, a Caxemira, ou seja, torna-se um problema de soberania territorial.

Não se pode olvidar que o CPEC dá à China autonomia decisória sobre o uso estratégico do Índico, uma vez que o porto de Gwadar lhe confere status autônomo de uso e ajuda o país a resolver o dilema do estreito de Malaca ${ }^{14}$, além de garantir um porto próximo ao Estreito de Ormuz e Golfo Pérsico - região pela qual passa a maior parte do petróleo importado pela China.

É importante salientar que os vizinhos indianos, Nepal, Bangladesh, Sri Lanka e Maldivas, já se associaram a BRI (PANT; PASSI, 2017). Porém, considerando os enormes obstáculos geopolíticos, parece que uma possível participação indiana no ambicioso projeto geoeconômico chinês não deve acontecer. Assim sendo, uma das alternativas à BRI é a parceria que vem sendo trabalhada com o Japão para oferecer outra proposta de integração logística e econômica no continente asiático (BORAH, 2019).

Nesse sentido, o Corredor de Crescimento Ásia-África, lançado por Modi e substanciado por um documento de visão conjunta indo-japonesa durante a $52^{\mathrm{a}}$ reunião anual do Banco Africano de Desenvolvimento, é um passo nessa direção. A Índia também permanece comprometida com o Corredor Internacional de Transporte Norte-Sul - um sistema proposto de transporte multimodal de 7.200 quilômetros (marítimo, ferroviário e rodoviário) que conecta o Oceano Índico e o Golfo Pérsico ao Mar Cáspio, através do Irã à Rússia e ao norte da Europa - embora o progresso em direção à sua operacionalização permaneça lento. Se a Índia perceber e capitalizar mais opções que não envolvam a China, poderemos acabar vendo uma resposta indiana que não é circunscrita pelos contornos da BRI (CLARKE, 2017).

Haveria uma suspeita por parte de alguns policymakers indianos de que a BRI foi concebida como um instrumento para o aumento da influência geopolítica chinesa (PANT; PASSI, 2017). Nesse sentido, o ministro das Relações Exteriores da Índia, o diplomata e filho do grande estrategista K. Subrahmanyam, S. Jaishankar, assim afirma:

Para nós, esta é uma iniciativa nacional chinesa. Os chineses a conceberam, criaram um plano. Não foi uma iniciativa internacional que eles discutiram com o mundo, com países interessados ou afetados por ela (...). Uma iniciativa nacional é criada com interesses nacionais, não cabe a outros comprá-la. A nossa posição é que, se isso é algo sobre o qual eles querem uma participação maior, eles precisam ter discussões maiores, e isso não aconteceu (JAISHANKAR, 2015, online, tradução nossa ${ }^{15}$.

\footnotetext{
$14 \mathrm{O}$ problema do Estreito de Malaca é que é uma região geopoliticamente vulnerável, pois pode ser bloqueado ou ter seu acesso dificultado em caso de conflito com a Índia ou Estados Unidos e comprometer o grande fluxo de comércio que passa por ali.

${ }_{15}$ No original: "this is a national Chinese initiative. The Chinese devised it, the Chinese created a blueprint ... and a national initiative is devised with national interests. It is not incumbent on others to buy it ... if this is something on which they want a larger buy-in, then they need to have larger discussions, and those haven't happened".
} 
Em 2019, o ministro reiterou a postura indiana de não adesão à BRI, alegando a questão sobre a soberania indiana na Caxemira e ao corredor econômico com o Paquistão (JAISHANKAR, 2019).

Outro ponto importante criticado pelo governo indiano é a armadilha da dívida (debt trap), que condena os países que aderiram à BRI, como Sri Lanka ou Mianmar, a uma dependência econômica, mas igualmente concede à China uma vantagem geopolítica em outras questões que possam envolver esses mesmos países amarrados na teia da dívida com a China.

Todavia, a despeito das críticas e declarações contrárias à BRI, a iniciativa pode ser a grande oportunidade para os investimentos tão necessários em infraestrutura na Índia. Haveria uma possibilidade real de ganhos caso o país resolvesse aderir ao megaprograma de investimentos chineses (JAH, 2016). O autor vai mais além ao dizer que:

O fato incontestável de hoje é que a China tem capital financeiro, tecnologia e, acima de tudo, a necessidade esmagadora, em seu próprio interesse nacional, de acelerar o desenvolvimento desses países a uma extensão que não poderia ser imaginada nem mesmo em meia década atrás. Também é um fato incontestável que os túneis, estradas e ferrovias que ele pretende construir perfuram as muralhas naturais do sul da Ásia, o Himalaia e acabam com a hegemonia geográfica da Índia sobre o resto do sul da Ásia. (JAH, 2016, online, tradução nossa' ${ }^{16}$ ).

A adesão indiana à BRI poderia facilitar, outrossim, o acesso a mercados da Ásia Central e outras economias envolvidas no projeto geoeconômico chinês, além do quê, a Índia poderia transformar-se em um dos nós da importante rede comercial criada. Outro ponto relevante seria o possível isolamento comercial do país ao não aderir à BRI, pois a conexão econômica e a infraestrutura gerada não integrariam a Índia, gerando consequências negativas à economia indiana (PANT; PASSI, 2017).

Há, portanto, a despeito dos problemas e limitações citados acima, espaço para ganhos indianos na BRI? Pant e Passi especulam acerca dos possíveis acessos a rotas de comércio abertos pela iniciativa e salientam que, caso a China faça concessões às demandas indianas quanto ao CPEC, seria possível uma cooperação no âmbito da BRI (PANT; PASSI, 2017).

Importante líder do Partido do Congresso (INC, em inglês), oposição ao governo Modi, declarou em mais de uma oportunidade que a Índia deveria participar do projeto BRI, pois não há nada a perder em tal iniciativa. A não inclusão do país no projeto seria uma grave falha na política externa em vigor (TEWARY, 2017). Esta é a mesma percepção do líder do partido Comunista indiano, que argumenta que a não participação na BRI pode isolar o país (KARAT, 2017).

\footnotetext{
${ }^{16}$ No original: "The incontrovertible fact today is that China has the finance capital, the technology and above all the overwhelming need, in its own national interest, to accelerate the development of these countries to an extent that could not have been imagined even half a decade ago. It is also an incontrovertible fact that the tunnel, road and rail links that it intends to build will pierce the natural ramparts of South Asia, the Himalayas, and end India's geographical hegemony over the rest of south Asia”.
} 
Um questionamento relevante deve ser colocado: a Índia consegue fazer frente ao imenso poder de influência e pressão chinês na região? "Se não puder superar seu inimigo, junte-se a ele". Seria esta a estratégia indiana de conformação ao projeto de poder de Beijing ou há uma alternativa juntamente com outros parceiros críticos da iniciativa BRI, como Estados Unidos e Japão?

A BRI seria um projeto de conectividade econômica via uma grande rede de infraestrutura que responde à necessidade chinesa de aportar seu excesso de capital e capacidade industrial, aproveitar a demanda externa e exportar serviços, bem como garantir influência política. Ou seja:

OBOR é um meio de estender esferas de influência política, principalmente na África atualmente, para o Sudeste Asiático, Sul da Ásia, Ásia Central e Oeste da Ásia. Trata-se de comprar liderança regional na busca pela hegemonia. Acima de tudo, é um trampolim para as aspirações da China à liderança global, criando um rival à área econômica transatlântica, com os EUA em seu ápice (NAYYAR, 2017, online, tradução nossa ${ }^{17}$ ).

\section{CONSIDERAÇÕES FINAIS}

Buscamos analisar neste trabalho a difícil missão da Índia de tirar proveito das disputas de poder entre Estados Unidos e China. A postura de terceiro interessado traz consigo alguns elementos relevantes, que foram analisados e apresentados, como a parceria indo-estadunidense para a contenção da expansão da influência chinesa e suas limitações devido à postura ambivalente dos Estados Unidos frente à Índia; ou ainda, os desafios indianos a uma inserção mais autônoma e sua incapacidade de agir como grande potência.

Para Mohan, à medida que a Índia se torna uma potência cada vez mais global, novas responsabilidades surgem como consequência, o que coloca em xeque a tradição e a postura de uma política externa terceiro-mundista (MOHAN, 2010b). Todavia, é justamente esta postura que preserva, em alguma medida, o poder de barganha indiano em temas nos quais o país ainda não é competitivo ou poderoso, como o comércio internacional, e mesmo a capacidade militar.

O crescimento econômico pujante e constante, aliado ao fator demográfico e ao incremento do poder militar devem contribuir para a transformação indiana em uma potência global. A despeito dos inúmeros desafios, como pobreza, desigualdades sociais e religiosas (a questão das castas), infraestrutura precária e gestão pública pouco eficaz, o país tem conseguido ampliar seus instrumentos de poder de maneira considerável. Antes dos anos 2000, pouco se ouvia falar a respeito do poder naval ou espacial indiano - hoje o país dispõe de submarinos nucleares, navios

\footnotetext{
${ }_{17}$ No original: "Obor is a means of extending political spheres of influence, mostly in Africa at present, to South East Asia, South Asia, Central Asia and West Asia. It is about buying regional leadership in the quest for hegemony. Above all, it is a stepping stone for China's aspirations of global leadership by creating a rival to the transatlantic economic area with the US at its apex".
} 
aeródromos e mísseis antissatélites. Há grande expectativa de que o país assuma responsabilidades cada vez maiores nos temas da agenda global e esteja presente na resolução dos problemas mundiais com mais naturalidade. Ser uma "potência responsável”, como sugere Amrita Narlikar e Raja Mohan não passa, necessariamente, pelo abandono de uma estratégia autonomista, mas, sim, fazer com que a ordem internacional reconheça sua presença e interesses nacionais.

Desse modo, a busca indiana por mais autonomia nas relações internacionais deve ter em conta que seus interesses estratégicos não podem estar circunscritos às oscilações da política externa estadunidense, pois tendem, à medida que seu poder econômico e militar aumentam, a colidir cada vez mais com os da superpotência mundial; e o preço da contenção chinesa não pode ser o de dependência junto aos Estados Unidos. Com efeito, além disso, nada impede que, no futuro, as relações com a China, devido à cooperação econômica da BRI, tornem-se preferenciais e, portanto, venham a afetar as relações com os estadunidenses. Assim, a Índia, como uma potência regional com aspirações globais, não pode prender-se às estratégias geopolíticas de outros Estados, com o risco de comprometer seu objetivo precípuo, qual seja, o aumento da autonomia na sua inserção internacional. Para a consecução desta meta, o país terá de agir com pragmatismo, tirando o máximo de proveito como terceiro interessado nas relações sino-estadunidenses, isto é, deverá extrair as vantagens alcançáveis na contenção das ameaças chinesas, porém, observando, outrossim, os benefícios que a China está disposta a conceder à Índia, em função da participação desta na BRI.

A Índia ainda não está pronta para assumir o papel de potência mundial, pois lhe faltam os predicados necessários, porém, o caminho à ascensão no SI dependerá dos desdobramentos da disputa hegemônica entre Estados Unidos e China, mas, sobretudo, da capacidade interna do país de conseguir realizar as mudanças estruturais (desenvolvimento socioeconômico e militar) necessárias que auxiliarão na construção da sua política externa autônoma de potência.

* Artigo recebido em 11 de dezembro de 2019, aprovado em 13 de abril de 2020.

\section{REFERÊNCIAS}

AKHTAR, Shayerah Ilias; KRONSTADT, K. Alan. US-India Trade Relations. Congressional Research Service (CRC), 14, Fev. 2020. Disponível em: https://fas.org/sgp/crs/row/IF10384.pdf. Acesso em: 11/04/2020.

BARUAH, D. M. Asia's Nightmare: Could India and China Clash over the South China Sea?'. The National Interest, v. 14, 2015.

BURGESS, Stephen. The US Pivot to Asia and Renewal of the US-India Strategic Partnership. Comparative Strategy, v. 34, n. 4, p. 367-379, 2015. 
BURNS, John F. India's New Defense Chief Sees Chinese Military Threat. New York Times, v. 5, 1998.

CLARKE, Michael et al. China's Belt and Road Initiative: Views from along the Silk Road. Asia policy, n. 24, p. 65-122, 2017.

ELIAS, Norbert. O Processo Civilizador 2: formação do Estado e civilização. Zahar, 1993.

GADY, Franz-Stefan . India Approves Procurement of 10 More P-8I Maritime Patrol Aircraft. The Diplomat, 26, Jun. 2019. Disponível em: < https://thediplomat.com/2019/06/india-approvesprocurement-of-10-more-p-8i-maritime-patrol-aircraft/>. Acesso em: 10/04/2020.

GE, Huang. India's BRI rejection means lost opportunities: experts. Global Times, 04/Ago. 2019. Disponível em

http://www.globaltimes.cn/content/1145086.shtml\#targetText=China\%2DIndia\%2otrade\%2oros e\%2013.2,the\%20Chinese\%20Ministry\%200f\%20Commerce. >. Acesso em: 08/10/2019.

GLOBAL FIRE POWER. India Military Strength. GFP, 2019. Disponível em: < https://www.globalfirepower.com/country-military-strengthdetail.asp?country id=india $>$. Acesso em: 25/06/2019.

China Military Strength. GFP, 2019. Disponível em: < https://www.globalfirepower.com/country-military-strength-detail.asp?country $\mathrm{id}=$ china $\quad>$. Acesso em: 25/06/2019.

GOLDSTEIN, Avery. Rising to the challenge: China's grand strategy and international security. Stanford University Press, 2005.

GORDON, G. Chang. Clash of titans: India's 'Act east'Policy meets China's Maritime Silk road in the South China Sea'. Journal of Political Risk, v. 3, n. 6, 2015.

JAISHANKAR, Subrahmanyam. India won't join BRI, it's concept won't apply to us. The Economic Times, 04, Out. 2019. Disponível em: < https://economictimes.indiatimes.com/news/politics-and-nation/india-wont-join-bri-its-conceptwont-apply-to-us-jaishankar/articleshow/71441347.cms >. Acesso em: 05/10/2019.

IISS Fullerton Lecture by Dr. S. Jaishankar, Foreign Secretary in Singapore. Ministry of External Affairs, 2015. Disponível em: < https://www.youtube.com/watch?v=et2ihw8jHaY >.

JHA, Prem Shankar. Why India must embrace China's One Belt One Road plan. The Wire, 2016.

KARAT, P. Belt and Road initiative: Blinkered view of government. People's Democracy, 21, Mai. 2017. Disponível em: <https://peoplesdemocracy.in/2017/0521 pd/belt-and-road-initiativeblinkered-view-government $>$. Acesso em: 08/10/2019.

KAURA, Vinay. US-India Relations at the Crossroads - Can the growing US-India partnership survive 'America First'? The Diplomat, 24/06/2019. Disponível em: < https://thediplomat.com/2019/06/us-india-relations-at-the-crossroads/ >. Acesso em 01/07/2019.

KHURANA, Gurpreet S. China's 'String of Pearls' in the Indian Ocean and Its Security Implications. Strategic Analysis, v. 32, n. 1, p. 1-39, 2008. 
KNODELL, K. China's worst nightmare: Is a US-India military alliance brewing. The National Interest, Maio, 2016. Disponível em: < https://nationalinterest.org/blog/the-buzz/chinas-worstnightmare-us-india-military-alliance-brewing-16301 >. Acesso em: 22/05/2019.

MADAN, Tanvi. The US-India Relationship and China. Brookings, 23, Set. 2014. Disponível em: https://www.brookings.edu/research/the-u-s-india-relationship-and-china/. Acesso em: $19 / 04 / 2020$

MOHAN, Raja. India's new role in the Indian Ocean. Paper presented at Seminar (617): India 2009, Janeiro de 2010. Disponível em: < https://www.indiaseminar.com/2011/617/617 c raja mohan.htm >. Acesso em: 26/06/2019.

. Rising India: partner in shaping the global commons? The Washington Quarterly, v. 33, n. 3, p. 122-148, 2010.

India and the changing geopolitics of the Indian Ocean. Maritime Affairs, v. 6, n. 2, p. 1-12, 2010.

MUNI, S. D. India's" Look East" Policy: The Strategic Dimension. In: Perspectives on South Asian Security. 2013. p. 67-99.

NALAPAT, M. China's Great Game. Also M. Malik,'China's Strategy of Containing India', Power and Interest News Report, v. 6, 2006.

NAYYAR, Deepak. A corrida pelo crescimento-Países em desenvolvimento na economia mundial. Rio de Janeiro: Contraponto, 2014.

. One Belt, One Road has no basis in China's history. Livemint, 09, Jun. 2017. Disponível em: < https://www.livemint.com/Opinion/lrHNZQcdLcDN2eTtmbCocK/One-Belt-One-Roadhas-no-basis-in-Chinas-history.html > . Acesso em: 11/11/2019.

NYE, Joseph S. A Time for Positive-Sum Power. The Wilson Quarterly, v. 42, n. 4, 2018.

PANDA, Ankit. US-India Ties in Modi's Second Term: Charting a New Course? The Diplomat, 26/o6/2019. Disponível em: < https://thediplomat.com/2019/06/us-india-ties-in-modis-secondterm-charting-a-new-course/>. Acesso em: 26/o6/2019.

. What the Recently Concluded US-India COMCASA Means. The Diplomat, 09/09/2018. Disponível em: < https://thediplomat.com/2018/09/what-the-recently-concludedus-india-comcasa-means/ > . Acesso em: 08/02/2019.

PANT, Harsh V.; PASSI, Ritika. India's Response to China's Belt and Road Initiative: A Policy in Motion. Asia Policy, v. 24, n. 1, p. 88-95, 2017.

PANT, Harsh V.; SUPER, Julie M. India's 'non-alignment'conundrum: a twentieth-century policy in a changing world. International Affairs, v. 91, n. 4, p. 747-764, 2015.

RAJAGOPALAN, Rajesh. India's Strategic Choices: China and the Balance of Power in Asia. Carnegie Endowment for International Peace, 2017.

RICE, Condoleezza. Promoting the national interest. Foreign Affairs, v. 79, p. 45, 2000. 2-26, 2008 .

. Rethinking the national interest: American realism for a new world. Foreign Affairs, p. 
SATALINE, Suzanne. Trump Has Started a Brain Drain Back to India. Foreign Policy, last modified September, v. 22, 2017.

SCOTT, David. The great power 'great game' between India and China: 'The logic of geography'. Geopolitics, v. 13, n. 1, p. 1-26, 2008.

SINDWANI, Prerna. Trump government agrees to sell naval guns worth $\$ 1$ billion to India. Business Insider, 21, Nov. 2019. Disponível em : < https://www.businessinsider.in/policy/news/trump-government-agrees-to-sell-naval-guns-worth1-billion-to-india/articleshow/72166598.cms $>$. Acesso em: 21/21/2019.

SINGH, Udai Bhanu. Significance of India's Act East Policy and Engagement with ASEAN. IDSA, 04/12/2018. Disponível em: < https://idsa.in/backgrounder/significance-indiaact-east-policy-and-engagement-with-asean-ubsingh 041218>. Acesso em: 25/04/2019.

SIPRI. Global arms industry: US companies dominate the Top 1oo; Russian arms industry moves to second place. Stockholm International Peace Institute, 18, Dez. 2018. Disponível em: < https://www.sipri.org/media/press-release/2018/global-arms-industry-uscompanies-dominate-top-100-russian-arms-industry-moves-second-place $>. \quad$ Acesso em: 11/04/2020.

THE ECONOMIC TIMES. Indian Navy aiming at 2oo-ship fleet by 2027. Disponível em: $</ /$ economictimes.indiatimes.com/articleshow $/ 48072917 . \mathrm{cms}$ ?from $=$ mdr\&utm source $=$ conte ntofinterest\&utm medium=text\&utm campaign=cppst $>$. Acesso em: 01/07/2019.

. Us surpasses China to become India's top trading partner. The Economic

Times, 23, Fev. 2020. Disponível em:
https://economictimes.indiatimes.com/news/economy/foreign-trade/us-surpasses-china-tobecome-indias-top-trading-partner/articleshow/74264765.cms?from $=\mathrm{mdr}$. $\quad$ Acesso em: 09/04/2020.

TEWARI, Manish. OBOR is the Grandest Failure of Indian Foreign Policy. The Indian Express (Online). 17. Mai. 2017.

VAJPAYEE, Atal Bihari. Nuclear Anxiety; Indian's Letter to Clinton on the Nuclear Testing. New York Times, v. 13, 1998.

WAGNER, Alex. Bush waives nuclear-related sanctions on India, Pakistan. Arms Control Today, v. 31, n. 8, p. 20, 2001.

WEISS, Leonard. US-India nuclear cooperation: Better later than sooner. Nonproliferation Review, v. 14, n. 3, p. 429-457, 2007. 